\title{
Ultrasound Evaluation of Radial Nerve Palsy Associated with Humeral Shaft Fractures to Guide Operative Versus Non-Operative Treatment
}

\author{
Melissa Esparza ${ }^{1}$, Jason R. Wild ${ }^{1}$, Christopher Minnock ${ }^{2}$, Kurt M. Mohty ${ }^{1}$, Lisa M. \\ Truchan $^{1}$, Mihra S. Taljanovic ${ }^{1}$
}

${ }^{1}$ University of Arizona/Banner University Medical Center, Tucson, AZ, USA. Departments of Orthopaedics (ME, LMT, JRW, KMM) and Department of Medical Imaging (MST), ${ }^{2} \mathrm{DMC}$ Children's Hospital of Michigan, Detroit, MI, USA (CM)

\author{
Correspondence: \\ melissa.esparza@gmail.com \\ Tel.: + 15204658107 \\ Fax.: + 15206262668
}

Received: 1 February 2019 Accepted: 9 May 2019

Key Words: Humerus Fracture Ultrasound • Radial Nerve • Injury.
Objective. To determine the effectiveness of diagnostic ultrasound (US) at evaluating the condition of the radial nerve in the setting of humeral shaft fractures. Materials and Methods. An observational study was performed of 18 patients with radial nerve palsy associated with humeral shaft fractures who underwent US examination to assess the condition of the radial nerve. Results. Six patients with humeral shaft fractures treated nonoperatively in a functional brace had US findings consistent with contusion or stretch radial nerve injury. Twelve patients ultimately underwent surgery either because US showed an entrapped or lacerated radial nerve, or for other operative indications. There was a $92 \%$ concordance (11/12 patients) between US and intraoperative findings with regards to the condition and location of the radial nerve, with the remaining case being complicated by delayed surgical treatment secondary to patient factors. Conclusion. Our study demonstrates that US is an effective diagnostic tool in evaluating radial nerve injuries in the setting of humeral shaft fractures and can aid in clinical decision making by differentiating between patients with nerve laceration or entrapment who may benefit from surgery from those with neurapraxia managed nonoperatively.

\section{Introduction}

Injuries to the radial nerve in the setting of humeral shaft fractures are among the most common peripheral nerve lesions associated with trauma (1-5). The intimate relationship of the radial nerve with the shaft of the humerus within the spiral groove makes it particularly vulnerable to traction, transection, or entrapment injuries with fractures of the middle and distal third of the humerus $(6,7)$. Humeral shaft fractures are commonly treated non-operatively owing to Dr. Sarmiento's extensive work and research with the functional brace (8). When there is an associated radial neuropathy, nonoperative management of the humeral shaft fracture and expectant management of the nerve palsy remain the most common treatment recommendation $(2,4,5,7)$. In a systematic review of studies of humeral shaft fractures associated with radial nerve palsy, Shao et al. report a prevalence of radial nerve palsy of $11.8 \%$. They report a spontaneous recovery rate of $70.7 \%$ from their meta-analysis of 532 radial nerve palsies in 4517 fractures (3). Other studies have reported spontaneous nerve recovery rates as high as $89 \%$ (9). 
Delayed return of radial nerve function is commonly evaluated with electromyography $(\mathrm{EMG})(3,10)$.

Diagnostic peripheral nerve ultrasound (US) has gained popularity due to its costeffectiveness and non-invasive nature with very low risk (11). This imaging modality not only has the ability to determine if a nerve is intact, but it can reveal the precise location of the nerve in relationship to bone or other structures as well as show inflammatory changes within and about the nerve $(11,12)$. US evaluation of the radial nerve in the setting of humeral shaft fracture allows for differentiation of nerve injury secondary to contusion or stretch injury versus laceration or entrapment within the fracture site $(3,13-15)$. If signs of nerve transection, partial-thickness tear or entrapment are identified, a change of management may be indicated with conversion to early exploration and operative fracture fixation to prevent delayed treatment and problematic healing of the fracture with interposed nerve tissue. Our study examines the utility of US evaluation of the radial nerve in cases of humeral shaft fractures associated with radial nerve palsy. We explore the correlation of US findings to the actual state of the nerve observed intraoperatively.

The purpose of this study is to determine the effectiveness of diagnostic US at evaluating the condition of the radial nerve in the setting of humeral shaft fractures and to discuss whether this information may help guide surgeons in their clinical decision making for operative versus nonoperative treatment of these injuries.

\section{Materials and Methods}

Institutional Review Board approval was obtained for this observational study. A retrospective review was conducted of patients with humeral shaft fracture who had undergone US evaluation of the radial nerve from
2012-2015. Subsequent eligible patients from January 2015-December 2017 were enrolled in the study prospectively. All patients age 18 years and older who presented to our institution with a humeral shaft fracture and had an initial examination concerning for radial nerve palsy were included in the study. In addition, patients with a humeral shaft fracture that the treating surgeon deemed operative in nature were also eligible for study enrollment for as a control group to obtain US evaluation of presumably normal radial nerves. Operative indications for humeral shaft fractures included open fractures, fractures with associated vascular injury requiring surgical repair, and ipsilateral extremity fractures or polytrauma patients who would undergo surgery for improved mobilization of the extremity. Other relative indications for surgery included patient preference/desire for earlier mobilization, body habitus, and inability to tolerate a brace. Exclusion criteria included any pre-existing compromise to radial nerve function.

All US examinations were performed in the Department of Medical Imaging on Logiq E9 US machine (General Electric Healthcare, Chicago, Illinois, USA) with 6-15 $\mathrm{MHz}$ high-resolution multifrequency linear transducer by a musculoskeletal (MSK) trained US technologist and one of four fellowship trained musculoskeletal radiologists. On the US images, the radial nerves were considered normal when they showed a stippled honeycomb appearance on the short axis US images with hypoechoic areas corresponding to the nerve fascicles and surrounding hyperechoic rims corresponding to endoneurium, perineurium, and epineurium. Normal nerves appear hypoechoic with alternating hyperechoic bends on the long axis US images. Completely transected nerves show focal hypoechoic bulbous thickening at their ends consistent with stump neuromas. Partially torn nerves appear hypoechoic and irregular 

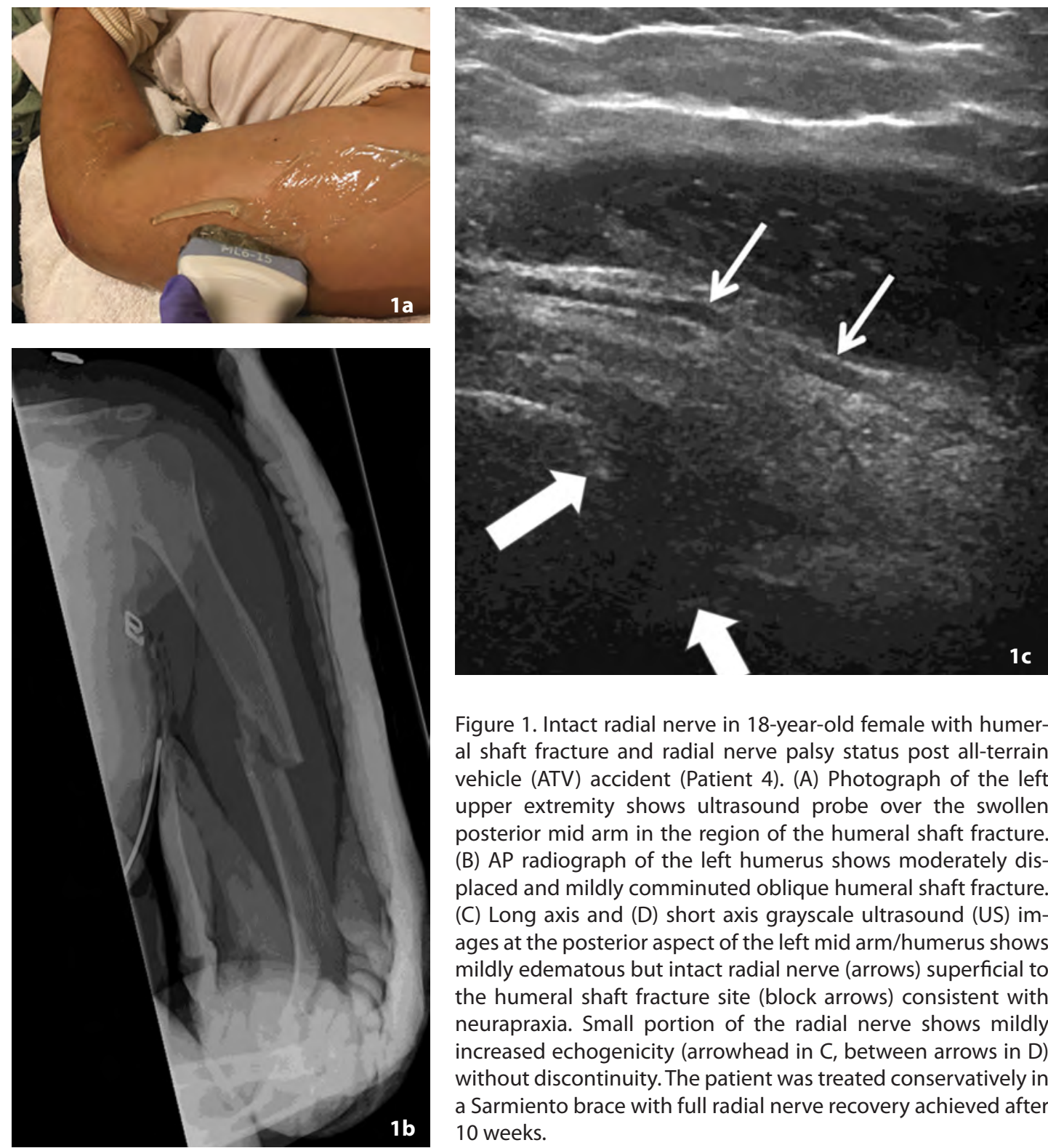

Figure 1. Intact radial nerve in 18-year-old female with humeral shaft fracture and radial nerve palsy status post all-terrain vehicle (ATV) accident (Patient 4). (A) Photograph of the left upper extremity shows ultrasound probe over the swollen posterior mid arm in the region of the humeral shaft fracture. (B) AP radiograph of the left humerus shows moderately displaced and mildly comminuted oblique humeral shaft fracture. (C) Long axis and (D) short axis grayscale ultrasound (US) images at the posterior aspect of the left mid arm/humerus shows mildly edematous but intact radial nerve (arrows) superficial to the humeral shaft fracture site (block arrows) consistent with neurapraxia. Small portion of the radial nerve shows mildly increased echogenicity (arrowhead in C, between arrows in D) without discontinuity. The patient was treated conservatively in a Sarmiento brace with full radial nerve recovery achieved after 10 weeks.

while contused nerves appear hypoechoic, heterogeneous and thickened. Entrapped nerves dive into the fracture site. Because of significant pain and discomfort in the setting of the acute humeral shaft fractures, all patients were examined in the supine position on the ultrasound stretcher or in the hospital bed with their affected arm at the examiner's side. Figure 1 demonstrates patient positioning, humeral shaft fracture, and the US technique utilized in this study in a patient and representative US images of their intact radial nerve.

The radial nerves were first traced along their short axis using the "elevator" technique for rapid screening of long nerve segments and after that along their long axis throughout the arm to their bifurcation into the superficial and deep branches at the anterior aspect of the elbow proximal to the 
supinator muscle. For completeness of the US exam the superficial and deep radial nerve branches were then traced along the patient's forearm using the same examination technique. On a case by case basis, pillows were placed under the patient's back at the examiners side to partially roll patient's body away from the examiner and enable better exposure of the examined upper extremity along the pathway of the radial nerve. Of note, in the non-acute trauma setting, the radial nerve can be examined with the patient in a sitting position.

Seventeen of 18 patients had their US imaging within 24 hours after injury. Patients with US diagnosis of radial nerve entrapment or laceration were treated with open reduction internal fixation (ORIF) of their humeral fracture. Patients were followed in clinic until they showed signs of nerve recovery or were lost to follow up. At the conclusion of the study, patients that had been lost to follow up were contacted via telephone.

\section{Results}

Eighteen patients were enrolled in the study (Table 1). The average age of patients was 48 years old (range 18-81), and $56.6 \%$ of patients were male. Mechanisms of injury included ground level fall (6), fall from several feet (3), motor vehicle or all-terrain vehicle (ATV) accidents (5), bicycle accidents (2), assault (1), and wrestling (1). Fourteen patients included in the study had a radial nerve palsy, four in the nonoperative bracing group and ten in the operative group. Two patients in the nonoperative group underwent US imaging because their initial clinical exam on presentation was concerning for radial nerve palsy however they were noted to have full recovery of the radial nerve function prior to hospital discharge.

\section{Treatment}

Eight patients with no US findings of radial nerve entrapment or laceration were initially treated with a functional brace. Of those eight, two subsequently went on to ORIF, one because of inability to tolerate the brace and one after developing a fracture nonunion. Six patients underwent ORIF due to US showing entrapment or laceration of the radial nerve (Figure 2). Four other patients underwent ORIF for other indications including polytrauma, pathologic fracture, and surgeon judgement.

\section{Ultrasound and Operative Findings}

Of the 12 patients who underwent ORIF, US findings were compared to intraoperative assessment of the radial nerve condition. There were six cases where US demonstrated an intact radial nerve, which was concordant with intraoperative findings. These patients served as a control group. This group included one case (Table 1, Patient 18) in which US reported a thickened but continuous nerve perched on the fracture site. Direct visualization during surgery confirmed nerve continuity with the distal fracture fragment tenting the nerve. US accurately diagnosed nerve entrapment or laceration in five cases that were concordant with intraoperative findings. In one patient (Table 1, Patient 8), US showed "a portion of the nerve which is not well seen, highly suggestive for entrapment and partial laceration". Operative findings confirmed partial nerve laceration and entrapment as seen in Figure 2. 

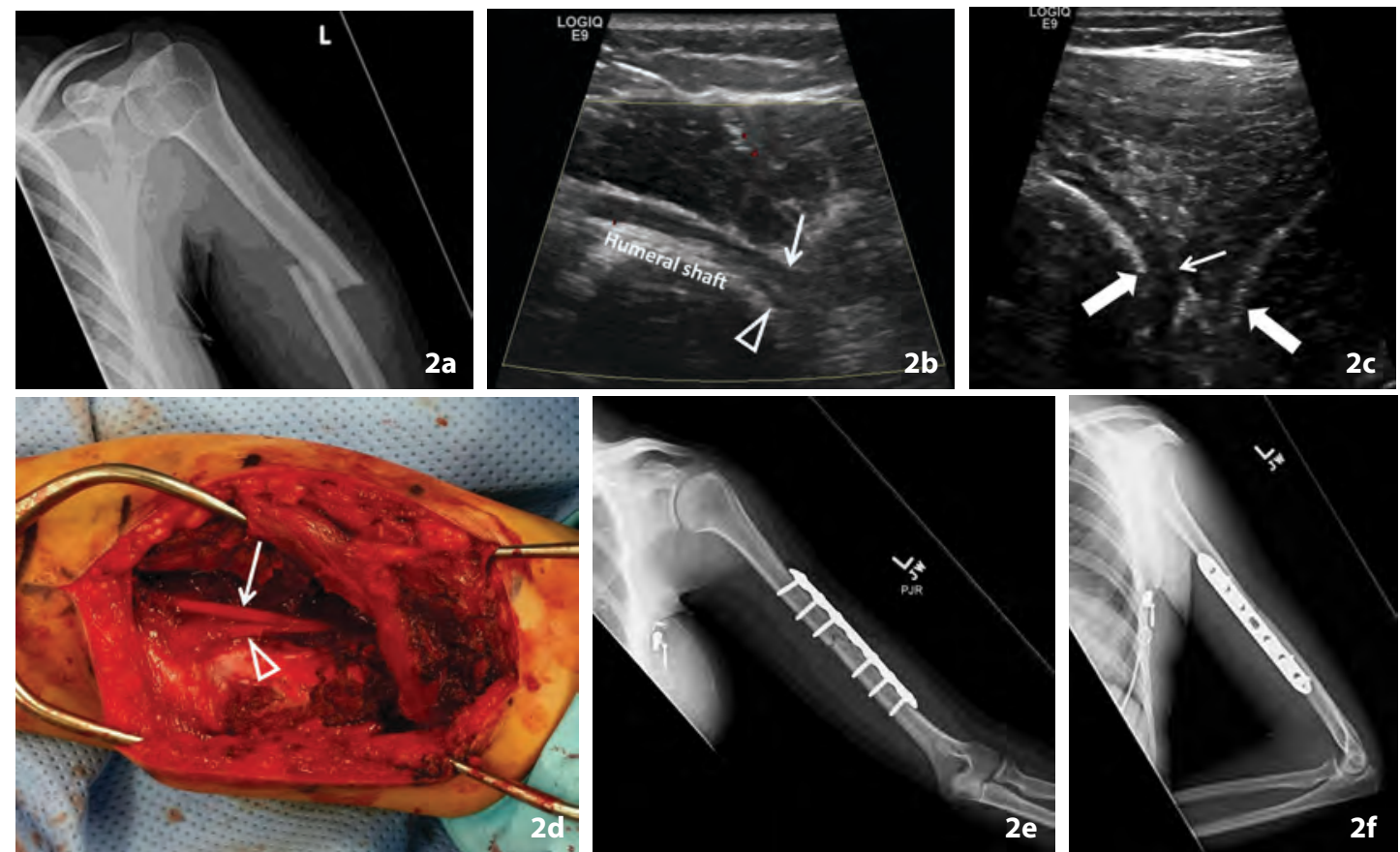

Figure 2. Transverse humeral shaft fracture with associated radial nerve entrapment and partial laceration in a 33-year-old female status post bicycle accident (Patient 8). (A) AP radiograph of the left humerus shows completely displaced mildly overriding humeral shaft fracture. (B) Long axis power Doppler US image at the level of the left humeral shaft fracture shows radial nerve entrapment at the fracture site (arrow) with partial laceration (arrowhead). (C) Long axis grayscale US image shows radial nerve entrapment (arrow) at the humeral shaft fracture site (block arrows). (D) Intraoperative photograph of the posterior aspect of the right arm confirmed radial nerve entrapment (arrow) and partial laceration (arrowhead) at the humeral shaft fracture site which correlates with the US findings. (E) AP and (F) lateral postoperative radiographs of the left humerus obtained two weeks later show a laterally applied low contact dynamic compression plate with 6 cortical screws transfixing the left humeral shaft fracture in anatomic alignment and without hardware complication. The patient achieved full radial nerve recovery at final follow up.

Table 1. Patient Information and Findings

\begin{tabular}{llllllll}
\hline Patients & $\begin{array}{l}\text { Age } \\
\text { (y) }\end{array}$ & Sex & $\begin{array}{l}\text { Mechanism } \\
\text { of injury }\end{array}$ & $\begin{array}{l}\text { Humerus } \\
\text { radiographs }\end{array}$ & Ultrasound findings & $\begin{array}{l}\text { Method of } \\
\text { treatment }\end{array}$ & $\begin{array}{l}\text { Operative } \\
\text { findings }\end{array}$ \\
\hline 1 & 38 & M & MVC & $\begin{array}{l}\text { Transverse } \\
\text { midshaft } \\
\text { with butterfly } \\
\text { fragment }\end{array}$ & $\begin{array}{l}\text { Difficult visualization secondary } \\
\text { to large body habitus however no } \\
\text { definitive entrapment seen as nerve } \\
\text { appears superficial to fracture site }\end{array}$ & $\begin{array}{l}\text { Functional } \\
\text { bracing }\end{array}$ & N/A* \\
\hline 2 & 31 & M & $\begin{array}{l}\text { Assaulted } \\
\text { with ice } \\
\text { pick }\end{array}$ & $\begin{array}{l}\text { Long spiral } \\
\text { comminuted } \\
\text { fracture }\end{array}$ & Normal appearance of radial nerve & $\begin{array}{l}\text { Functional } \\
\text { bracing }\end{array}$ & N/A \\
\hline 3 & 37 & M & $\begin{array}{l}\text { Ground } \\
\text { level fall }\end{array}$ & $\begin{array}{l}\text { Transverse } \\
\text { midshaft } \\
\text { fracture }\end{array}$ & $\begin{array}{l}\text { Stretched and mildly thickened radial } \\
\text { nerve with no evidence of entrapment }\end{array}$ & $\begin{array}{l}\text { Functional } \\
\text { bracing }\end{array}$ & N/A \\
\hline 4 & 18 & F & $\begin{array}{l}\text { ATV } \\
\text { accident }\end{array}$ & $\begin{array}{l}\text { Transverse } \\
\text { midshaft } \\
\text { fracture }\end{array}$ & $\begin{array}{l}\text { Radial nerve superficial to fracture site } \\
\text { without evidence of entrapment }\end{array}$ & $\begin{array}{l}\text { Functional } \\
\text { bracing }\end{array}$ & N/A \\
\hline 5 & 81 & M & $\begin{array}{l}\text { Fall from } \\
\text { bed }\end{array}$ & $\begin{array}{l}\text { Midshaft spiral } \\
\text { fracture }\end{array}$ & $\begin{array}{l}\text { Radial nerve edematous but } \\
\text { contiguous with no evidence of } \\
\text { transection or entrapment }\end{array}$ & $\begin{array}{l}\text { Functional } \\
\text { bracing }\end{array}$ & N/A \\
\hline 6 & 21 & F & $\begin{array}{l}\text { ATV } \\
\text { accident }\end{array}$ & $\begin{array}{l}\text { Transverse } \\
\text { midshaft } \\
\text { fracture }\end{array}$ & $\begin{array}{l}\text { Enlargement and irregularity of the } \\
\text { nerve with tenting at the fracture site }\end{array}$ & $\begin{array}{l}\text { Functional } \\
\text { bracing }\end{array}$ & N/A \\
\hline
\end{tabular}


Continuation of Table 1. Patient Information and Findings

\begin{tabular}{|c|c|c|c|c|c|c|c|}
\hline Patients & $\begin{array}{l}\text { Age } \\
\text { (y) }\end{array}$ & Sex & $\begin{array}{l}\text { Mechanism } \\
\text { of injury }\end{array}$ & $\begin{array}{l}\text { Humerus } \\
\text { radiographs }\end{array}$ & Ultrasound findings & $\begin{array}{l}\text { Method of } \\
\text { treatment }\end{array}$ & $\begin{array}{l}\text { Operative } \\
\text { findings }\end{array}$ \\
\hline 7 & 32 & M & Wrestling & $\begin{array}{l}\text { Oblique distal } \\
\text { shaft fracture }\end{array}$ & $\begin{array}{l}\text { Entrapment of a short segment of the } \\
\text { radial nerve between the proximal } \\
\text { aspect of the fracture fragments }\end{array}$ & ORIF & $\mathrm{RN}+$ \\
\hline 8 & 33 & $\mathrm{~F}$ & $\begin{array}{l}\text { Bicycle } \\
\text { accident }\end{array}$ & $\begin{array}{l}\text { Transverse } \\
\text { midshaft } \\
\text { fracture }\end{array}$ & $\begin{array}{l}\text { Radial nerve appears to dive towards } \\
\text { and into the fracture site with a portion } \\
\text { of the nerve not well-seen, highly } \\
\text { concerning for entrapment and partial } \\
\text { laceration }\end{array}$ & ORIF & $\mathrm{RN} \neq$ \\
\hline 9 & 33 & M & MVC & $\begin{array}{l}\text { Oblique } \\
\text { midshaft } \\
\text { fracture } \\
\text { with butterfly } \\
\text { fragment }\end{array}$ & $\begin{array}{l}\text { Nonvisualization of the radial nerve } \\
\text { at the fracture site concerning for } \\
\text { entrapment and transection, with } \\
\text { associated thickening of the nerve just } \\
\text { distal to the fracture }\end{array}$ & $\begin{array}{l}\text { ORIF } \\
\text { Tendon } \\
\text { transfers }\end{array}$ & RN§ \\
\hline 10 & 52 & $\mathrm{~F}$ & $\begin{array}{l}\text { Fall from } \\
\text { truck }\end{array}$ & $\begin{array}{l}\text { Spiral fracture } \\
\text { of distal shaft } \\
\text { with butterfly } \\
\text { fragment }\end{array}$ & $\begin{array}{l}\text { Findings concerning for radial nerve } \\
\text { entrapment at the level of the fracture } \\
\text { with mild diffuse enlargement of the } \\
\text { visualized nerve }\end{array}$ & ORIF & $\mathrm{RN} \|$ \\
\hline 11 & 76 & $\mathrm{~F}$ & $\begin{array}{l}\text { Ground } \\
\text { level fall }\end{array}$ & $\begin{array}{l}\text { Long spiral } \\
\text { fracture of mid } \\
\text { to distal shaft }\end{array}$ & $\begin{array}{l}\text { Nonvisualization of the radial nerve at } \\
\text { the fracture site worrisome for radial } \\
\text { nerve entrapment }\end{array}$ & ORIF & RNף \\
\hline 12 & 74 & $\mathrm{~F}$ & $\begin{array}{l}\text { Ground } \\
\text { level fall }\end{array}$ & $\begin{array}{l}\text { Long spiral } \\
\text { fracture of } \\
\text { proximal to } \\
\text { midshaft }\end{array}$ & $\begin{array}{l}\text { 1st US: irregular, enlarged, edematous } \\
\text { radial nerve without discontinuity or } \\
\text { entrapment } \\
\text { 2nd US: abutment and possible } \\
\text { impingement of the nerve at the } \\
\text { posterior edge of the fixation plate } \\
\text { distally }\end{array}$ & $\begin{array}{l}\text { ORIF after } \\
\text { unable to } \\
\text { tolerate brace }\end{array}$ & $\mathrm{RN}^{* *}$ \\
\hline 13 & 59 & $\mathrm{~F}$ & $\begin{array}{l}\text { Ground } \\
\text { level fall }\end{array}$ & $\begin{array}{l}\text { Segmental } \\
\text { comminuted } \\
\text { midshaft } \\
\text { fracture }\end{array}$ & $\begin{array}{l}\text { Edematous radial nerve about the } \\
\text { fracture site without definitive evidence } \\
\text { of entrapment }\end{array}$ & $\begin{array}{l}\text { ORIF after } \\
\text { development } \\
\text { of nonunion }\end{array}$ & RN+† \\
\hline 14 & 60 & M & $\begin{array}{l}\text { Ground } \\
\text { level fall }\end{array}$ & $\begin{array}{l}\text { Oblique } \\
\text { midshaft } \\
\text { fracture with } \\
\text { butterfly } \\
\text { fragment }\end{array}$ & $\begin{array}{l}\text { 1st US: poor visualization of radial } \\
\text { nerve suggesting focal entrapment } \\
\text { 2nd US: findings consistent with partial } \\
\text { entrapment at region of posttraumatic } \\
\text { deformity }\end{array}$ & $\begin{array}{l}\text { ORIF } \\
\text { Tendon } \\
\text { transfers }\end{array}$ & $\mathrm{RN} \neq \neq$ \\
\hline 15 & 52 & $\mathrm{~F}$ & $\begin{array}{l}\text { Ground } \\
\text { level fall }\end{array}$ & $\begin{array}{l}\text { Spiral fracture } \\
\text { of distal shaft } \\
\text { with butterfly } \\
\text { fragment }\end{array}$ & $\begin{array}{l}\text { Thickened edematous nerve without } \\
\text { entrapment }\end{array}$ & $\begin{array}{l}\text { ORIF (surgeon } \\
\text { judgement)* }\end{array}$ & RN§§ \\
\hline 16 & 69 & M & $\begin{array}{l}\text { Fall from } \\
\text { bed }\end{array}$ & $\begin{array}{l}\text { Midshaft } \\
\text { oblique } \\
\text { fracture }\end{array}$ & $\begin{array}{l}\text { Unremarkable appearance of radial } \\
\text { nerve }\end{array}$ & $\begin{array}{l}\text { ORIF } \\
\text { (pathologic } \\
\text { fracture) }\end{array}$ & $\mathrm{RN} \neq \neq$ \\
\hline 17 & 68 & M & MVC & $\begin{array}{l}\text { Transverse } \\
\text { distal shaft } \\
\text { fracture }\end{array}$ & Mild nerve edema, no entrapment & $\begin{array}{l}\text { ORIF } \\
\text { (polytrauma) }\end{array}$ & $\mathrm{RN}||||$ \\
\hline 18 & 23 & M & $\begin{array}{l}\text { Bicycle } \\
\text { accident }\end{array}$ & $\begin{array}{l}\text { Comminuted } \\
\text { distal shaft } \\
\text { fracture }\end{array}$ & $\begin{array}{l}\text { Radial neve perched on distal fracture } \\
\text { fragment with mild thickening distally } \\
\text { but no evidence of laceration or } \\
\text { entrapment }\end{array}$ & $\begin{array}{l}\text { ORIF (surgeon } \\
\text { judgement)* }\end{array}$ & RNগ१ \\
\hline
\end{tabular}

ORIF=Open reduction internal fixation; ATV=All-terrain vehicle; MVC; Motor vehicle collision; *Not applicable; +Open reduction internal fixation performed based on surgeon judgement of healing potential of the fracture based on fracture pattern/alignment and/or patient factors: ‡Radial nerve entrapped at the fracture site with a small partial laceration involving approximately $10 \%$ of the nerve fascicles; §Radial nerve transected at level of fracture with the distal end frayed and crushed; ||Radial nerve entrapped within the fracture site anterior to the fracture, transposed in front of the humerus; ๆRadial nerve entrapped over a spike of the distal humeral fracture segment; **Radial nerve identified and protected. Postoperative radial nerve palsy managed expectantly; ††Radial nerve identified in posterior fascia adjacent to triceps, in con-

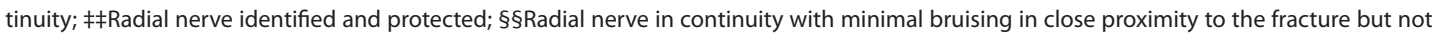
entrapped; ||||Radial neve visualized adjacent to fracture with evidence of trauma but in continuity; १ीApex of distal fracture fragment tenting and stretching the radial nerve. 
In one of the patients (Patient 14) with US findings consistent with radial nerve entrapment, surgery was delayed six weeks due to patient factors and systems issues. This patient did not undergo US examination at his initial presentation to the Emergency Department due to the unavailability of an MSK trained US technologist on a weekend evening. He was initially treated in a Sarmiento brace and instructed to have an US study performed the following week as an outpatient. The ultrasound was performed two weeks later and showed radial nerve entrapment. Despite US findings, this patient didn't follow-up in orthopaedic clinic until five weeks after his injury, at which time radiographs showed varus alignment of the fracture site with minimal callus formation. After that the patient underwent ORIF of the right humeral shaft fracture. Operative note described that the radial nerve was protected during the procedure however the condition of the nerve was not described in the operative report. Postoperatively this patient did not regain radial nerve function and ultimately underwent tendon transfers ten months later.

Based on results of our study, there was a 92\% (11/12 patients) concordance between US examination and intraoperative findings with regards to the condition and location of the radial nerve (including the six patients in the control group), with the remaining case being complicated by delayed surgical treatment secondary to patient factors.

\section{Orthopaedic Clinic Follow-up and Clinical Results}

There were two patients who did not follow up in orthopaedic clinic. Of the remaining 16 patients, mean follow up time was 13 weeks (range 2-40 weeks). Only 11 patients had greater than four weeks of follow up, all of whom went on to fracture union. Four of the six patients treated nonoperatively had full radial nerve function at their final clinic follow up visit. One patient had partial recovery of radial nerve function at her two week postoperative visit. Upon phone interview at nine months post-injury, she reported full motor recovery with remaining mild paresthesias that she felt were continuing to improve. The last of the six patients treated non-operatively was lost to follow-up.

Of the operatively treated group, six patients reported full radial nerve recovery and two patients reported partial recovery. Two patients underwent tendon transfers after initial fixation of their humeral shaft fracture. Another patient passed away two weeks postoperatively secondary to metastatic esophageal cancer, and the final patient in the operatively treated group did not have clinic or phone follow-up.

\section{Discussion}

Humeral shaft fractures associated with radial nerve palsies are a debilitating injury. Several studies have described a high level of disability and poor functional outcomes associated with upper extremity peripheral nerve injuries (16-18). Management of these injuries has traditionally been with expectant care as humeral shaft fractures frequently heal well with functional bracing and the majority of associated nerve palsies recover spontaneously. However, approximately $30 \%$ of patients with these injuries may not regain adequate radial nerve function with expectant management (3). Recovery for these patients may be long and cumbersome as radial nerve function is often monitored for 3-6 months before it is determined that the nerve will not recover spontaneously.

Some authors have advocated for more routine early nerve exploration for radial nerve palsies associated with humeral shaft fractures $(19,20)$. However, as the majority of nerve palsies recover spontaneously, routine nerve exploration would lead to 
overtreatment and even potential iatrogenic injury. Diagnostic US can help differentiate patients who would benefit from early nerve exploration, nerve repair, or acute tendon transfers from those patients expected to have spontaneous nerve recovery. Identification of this subset of patients who may benefit from early surgical intervention may help to decrease disability and improve recovery time for these patients.

Shao et al. (3) published a systematic review in 2005 of radial nerve palsy associated with humeral shaft fractures and presented an algorithm to guide treatment of these injuries. The algorithm includes US evaluation within three weeks of injury to assess the status of the radial nerve (3). If the nerve is continuous, loss of function is thought to be secondary to neurapraxia which may be managed conservatively. If the nerve is lacerated or entrapped, early surgical intervention is preferred as nerve function would not be expected to recover spontaneously. Depending on the condition and location of the entrapped and/or injured nerve, operative treatment could include simple extraction of the nerve from within the fracture site, nerve repair, or acute tendon transfers. If the nerve is severely contused or has an irreparable laceration, the likelihood of a prolonged or unpredictable recovery is high. In some cases, the nerve would not be expected to recover at al. In these settings, early tendon transfers may be beneficial in optimizing the patient's functional recovery by restoring active extension of the wrist and digits. For example, pronator teres to extensor carpi radialis brevis is an ideal transfer as it restores wrist extension while sacrificing few if any functional deficits given that the pronator teres muscle maintains its function as a pronator after transfer while also allowing the patient to be able to actively extend their wrist. This eliminates the necessity of prolonged wrist bracing that patients with a wrist drop secondary to radial nerve palsy would typically require in order to prevent a wrist flexion contracture.

In 2001 Bodner et al. conducted a prospective US study in 11 patients with humeral shaft fracture associated with radial nerve palsy (13). In this study the interval between trauma and US study was 1-8 weeks with a mean of 19 days which is different from our study in which 17 of 18 patients had their US studies within 24 hours of injury. It is more difficult to perform an US study in patients with hyperacute trauma with associated marked soft tissue edema and limited range of motion. However, we believe that prompt US examination of patients with acute humeral shaft fractures and associated radial nerve palsy during their initial evaluation in the emergency department may expedite clinical decision making of nonoperative versus operative treatment and avoid delays in surgical treatment.

There may be several challenges to implementing a protocol of routine prompt US evaluation for patients with humeral shaft fractures and associated radial nerve palsy. At our institution, MSK US studies are read by fellowship-trained MSK radiologists with experience in US evaluation of peripheral nerve injuries, however we recognize that not all institutions will have these resources available. Musculoskeletal US trained technologists or fellowship trained MSK radiologists are not routinely available at most institutions on nights and weekends. Patients may be instructed to follow up for an US examination on an outpatient basis, however issues of patient compliance, insurance coverage, etc. may delay evaluation or treatment.

There are several limitations to our study. Because US findings were used to help guide clinical decision making, surgeons were not blinded to the results of the US reports. This may introduce a degree of observer bias as surgeons' descriptions of intraoperative findings of the radial nerve may be influ- 
enced by their knowledge of the US findings. However, this limitation could not be avoided because the clinical decision making for nonoperative versus operative treatment was partially based on US findings.

The focus of this study was to evaluate the accuracy of US evaluation of the radial nerve in predicting intraoperative findings with a secondary goal of assessing clinical outcomes. However, our cohort had poor clinic follow-up, and for many patients we relied on phone calls and thus the patients' subjective impression of their arm function and symptoms in reporting of our final outcomes. A potential focus for future studies is to evaluate clinical outcomes to determine whether routine use of US in patients with radial nerve palsies associated with humeral shaft fractures may lead to faster recovery, improved function, and differences in health care costs.

We had a small sample size due to the relative infrequency of this injury. However, to our knowledge this is the largest case series in the literature evaluating US use for humeral shaft fractures associated with radial nerve injuries. We found a high concordance (92\%) between US and intraoperative findings describing the state of the radial nerve. Based on results of our study, we routinely perform US examination in patients with humeral shaft fractures associated with radial nerve palsy at our institution at the time of their initial presentation.

\section{Conclusion}

Diagnostic US is an effective and efficient method for evaluating the radial nerve in the face of humeral shaft fractures. US evaluation provides a means of separating patients with a radial nerve palsy due to laceration or entrapment where surgical intervention is indicated from those who have a neurapraxia that can be managed nonoperatively. Patients with radial nerve injuries not ex- pected to recover spontaneously may benefit from nerve repair or early tendon transfers. Earlier surgical intervention in this subset of patients may allow for earlier initiation of rehabilitation protocols, faster recovery, and reduced costs.

What Is Already Known on this Topic

The majority of radial nerve palsies associated with humeral shaft fractures may be treated nonoperatively with successful return of nerve function. However, injuries in which the radial nerve is lacerated or entrapped in the fracture site, as opposed to nerve palsies caused by contusion or stretch injuries, would not be expected to recover spontaneously and may require further treatment such as nerve repair or tendon transfers.

What this Study Adds

Our study demonstrates that US is an effective diagnostic tool in evaluating radial nerve injuries in the setting of acute humeral shaft fractures and can aid in clinical decision making by differentiating between patients with nerve laceration or entrapment who may benefit from surgery from those with neurapraxia managed nonoperatively.

Acknowledgements: Melissa Esparza, MD received a grant from the University of Arizona ACGME Resident Leadership Scholarship to support submission, presentation, travel expenses, etc. related to this project. No authors have any proprietary interests in the materials described in this article.

Authors' Contributions: Conception and design: $\mathrm{CM}, \mathrm{ME}$, JW and MT; Acquisition, analysis and interpretation of data: CM, ME, KM, JW, MT and LT; Drafting the article: CM and ME; Revising it critically for important intellectual content: ME, JW, MT, LT and CM; Approved final version of the manuscript: ME, JW, MT, LT, CM and KM.

Conflict of Interest: The authors declare that they have no conflict of interest.

\section{References}

1. Rockwood CA Jr, Green DP, Bucholz RW, Heckman JD. Rockwood and Green's Fracture in Adults. 4th ed. Philadelphia: Lippincott-Raven Publishers; 1996. p. 1043-5.

2. Crenshaw AH. Fracture of humeral shaft with radial nerve palsy. In: Crenshaw AH, editor. Campbell's Operative Orthopaedics, Vol. 2. 8th ed. St. Louis: Mosby Year Book; 1992. p. 1016.

3. Shao YC, Harwood P, Grotz MRW, Limb D, Giannoudis PV. Radial nerve palsy associated with 
fractures of the shaft of the humerus: A systematic review. J Bone Joint Surg Br. 2005;87(12):1647-52.

4. Pollock FH, Drake D, Bovill EG, Day L, Trafton PG. Treatment of radial neuropathy associated with fractures of the humerus. J Bone Joint Surg Am. 1981;63(2):239-43.

5. Bumbasirevic M, Lesic A, Bumbasirevic V, Cobeljic G, Milosevic I, Atkinson HD. The management of humeral shaft fractures with associated radial nerve palsy: a review of 117 cases. Arch Orthop Trauma Surg. 2010;130(4):519-22.

6. Holstein A, Lewis GM. Fractures of the Humerus with Radial-Nerve Paralysis. J Bone Joint Surg Am. 1963;45:1382-8.

7. Ekholm R, Ponzer S, Tornkvist H, Adami J, Tidermark J. The Holstein-Lewis humeral shaft fracture: aspects of radial nerve injury, primary treatment, and outcome. J Orthop Trauma. 2008;22(10):6937.

8. Sarmiento A, Kinman PB, Galvin EG, Schmitt $\mathrm{RH}$, Phillips JG. Functional bracing of fractures of the shaft of the humerus. J Bone Joint Surg Am. 1977;59(5):596-601.

9. Ekholm R, Ponzer S, Tornkvist H, Adami J, Tidermark J. Primary radial nerve palsy in patients with acute humeral shaft fractures. J Orthop Trauma. 2008;22(6):408-14.

10. Strandberg EJ, Mozaffar T, Gupta R. The Role of Neurodiagnostic Studies in Nerve Injuries and Other Orthopedic Disorders. J Hand Surg Am. 2007;32(8):1280-90.

11. Lawande AD, Warrier SS, Mukund SJ. Role of ultrasound in evaluation of peripheral nerves. Indian J Radiol Imaging. 2014;24(3):254-8.
12. Foxall GL, Skinner D, Hardman JG, Bedforth NM. Ultrasound anatomy of the radial nerve in the distal upper arm. Reg Anesth Pain Med. 2007;32(3):217-20.

13. Bodner G, Buchberger W, Schocke M, Bale R, Huber B, Harpf C, et al. Radial nerve palsy associated with humeral shaft fracture: evaluation with US-initial experience. Radiology. 2001;219(3):811-6.

14. Bodner G, Huber B, Schwabegger A, Lutz M, Waldenberger P. Sonographic detection of radial nerve entrapment within a humerus fracture. J Ultrasound Med. 1999;18(10):703-6.

15. Cartwright MS, Yoon JS, Lee KH, Deal N, Walker FO. Diagnostic ultrasound for traumatic radial neuropathy. Am J Phys Med Rehabil. 2011;90(4):342-3.

16. Novak CB, Anastakis DJ, Beaton DE, Katz J. Patient-reported outcome after peripheral nerve injury. J Hand Surg Am. 2009;34(2):281-7.

17. Novak CB, Anastakis DJ, Beaton DE, Mackinnon SE, Katz J. Biomedical and psychosocial factors associated with disability after peripheral nerve injury. J Bone Joint Surg Am. 2011;93(10):929-36.

18. Rivera JC, Glebus GP, Cho MS. Disability following combat-sustained nerve injury of the upper limb. Bone Joint J. 2014;96-B(2):254-8.

19. Nachef N, Bariatinskya V, Sulimovic S, Fontainea C, Chantelot C. Predictors of radial nerve palsy recovery in humeral shaft fractures: A retrospective review of 17 patients. Orthop Traumatol Surg Res. 2017;103(2):177-82.

20. Noaman H, Khalifa AR, El-Deen MA, Shiha A Early surgical exploration of radial nerve injury associated with fracture shaft humerus. Microsurgery 2008;28(8):635-42. 